Letrônica, Porto Alegre, v. 7, n. 1, p. 421-434, jan./jun., 2014

\title{
MEMÓRIAS DA GUERRA NA FICÇÃO BRASILEIRA CONTEMPORÂNEA: DISSOLUÇÃO DE UM PASSADO CONCRETO
}

\author{
MEMORIES OF WAR IN BRAZILIAN CONTEMPORARY FICTION: \\ DISSOLUTION OF A CONCRETE PAST
}

\author{
Regina Célia dos Santos Alves* \\ Willian André*
}

\begin{abstract}
Resumo: Este estudo tem por objetivo deitar olhos sobre certa vertente da ficção brasileira contemporânea que, em oposição à construção bem definida de um passado apreensível, opta por embrenhar-se pelas malhas da dissolução, tornando borrada/distorcida a memória da experiência vivida. Especificamente, pretendemos tratar, aqui, das memórias da guerra. Para tanto, serão analisados trechos de dois textos em prosa publicados na segunda metade do século XX, separados por certo intervalo temporal: o romance Vaca de nariz sutil (1961) de Campos de Carvalho, e a novela "O oco" (1973), de Hilda Hilst. Os narradores de ambos os textos pretendem construir memórias de uma guerra vivida, mas tais memórias prescindem de referências espaço-temporais precisas: sabemos apenas que houve a guerra, mas é impossível determinar quando ou onde ela ocorreu, e mesmo contra quem ou em razão de quê se lutava.
\end{abstract}

Palavras-chave: Memórias da guerra; Literatura brasileira contemporânea; Dissolução da identidade.

\begin{abstract}
This study aims at analyzing certain verve of contemporary Brazilian fiction that, opposing the building of an apprehensible past, chooses to drown through the meshes of dissolution, blurring/distorting the memory of one's experience. We intend to deal here specifically with the memories of war. For that, we are going to analyze excerpts from two fiction texts published in the second half of 20th century, separated by certain period of time: the novel Vaca de nariz sutil (1961), by Campos de Carvalho, and the novella "O oco" (1973), by Hilda Hilst. The narrators of both texts intend to build memories of a war they lived, but such memories lack precise space and time references: we only know that there was a war, but it is impossible do determine when or where it happened, and even against whom or the reason why they were fighting.
\end{abstract}

Keywords: Memories of war; Brazilian contemporary literature; Dissolution of identity.

\footnotetext{
* Doutora em Letras - Teoria Literária e Literatura Comparada pela Universidade Estadual Paulista Júlio de Mesquita Filho. Professora da Universidade Estadual de Londrina. E-mail: reginacsalves@hotmail.com.

* Doutorando em Letras - Estudos Literários pelo Programa de Pós-Graduação em Letras da Universidade Estadual de Londrina. Professor da Universidade Estadual do Paraná. E-mail: willianandreh@hotmail.com.
} 
0 ribombo da artilharia mistura-se ao uivo da besta luxuriosa, aos gritos de terror e de loucura, ao rugido de infâmia e ao vómito dos bêbados. Ao longe não cessa o crepitar das metralhadoras. Às esquinas estacam bandos com olhos atónitos de quem vê pela primeira vez realizados os seus sonhos. Aqui e ali a cidade deita as tripas à rua.

(Raul Brandão, Húmus)

Ao pensar a expressão "memórias de guerra", estabelecemos associação mais imediata com a memória coletiva, e não com a individual. Em linhas gerais, as memórias da guerra dizem respeito às memórias de um grupo ou nação: a depender do contexto, serão ressaltados feitos heróicos, valores e vitórias (é lugar comum a expressão "a guerra é contada por aqueles que venceram"), ou, no extremo oposto, as devastações, dores e traumas causados pelo conflito. Em ambos os casos, todavia, aquilo que se registra por escrito, enquanto memória de guerra, visa principalmente à constituição de "documentos" acessíveis às gerações futuras, à edificação de certa "memória coletiva", e também as obras de ficção que se dedicam ao tema, via de regra, desempenharão tal papel.

Partindo dessas considerações, o presente estudo tem por objetivo refletir sobre certa vertente da ficção brasileira contemporânea que parece posicionar-se na contramão da construção de uma memória da guerra de caráter documental, com detalhes concretos - impossibilitando, por exemplo, a associação entre memórias de guerra e memória coletiva, ou a interpretação da falta de memória como consequência da experiência traumática da guerra. Para tanto, estabelecemos dois recortes: o romance Vaca de nariz sutil (1961), de Campos de Carvalho, e a novela "O oco" (1973), de Hilda Hilst. Não é nossa pretensão constituir análises pormenorizadas de cada uma dessas obras. Ao contrário, interessam-nos aqui momentos específicos em que seus narradores, ambos homodiegéticos, procuram construir lembranças de certa guerra por eles vivida. Em oposição à constituição de um passado concreto, com dados e referências precisas, a tentativa de construção das memórias de guerra desses narradores resulta em falha: por brotarem de individualidades fragmentadas, sem contornos precisos, suas memórias tornam-se borradas, distorcidas. 0 máximo que se pode depreender de suas divagações é que houve, em algum momento, uma guerra. Não nos é dado saber, no entanto, onde 
ou quando o conflito ocorreu, nem tampouco contra quem ou por qual razão. Tal impossibilidade de se recuperar a experiência vivida aponta para um esfacelamento da subjetividade, e nos leva, em última instância, a refletir sobre a configuração do sujeito na narrativa ficcional contemporânea.

\section{Vaca de nariz sutil: o vazio depois da guerra}

Vaca de nariz sutil foi publicado por Campos de Carvalho em 1961. Em suas páginas, não encontramos referências precisas a tempo e espaço, e o narradorprotagonista não nos diz seu nome. Trata-se de um homem que voltou da guerra, e que vive em uma pensão, dividindo o quarto com um surdo-mudo, chamado Aristides. Seu principal passatempo é masturbar-se enquanto espia os outros moradores da pensão pelo buraco da fechadura das portas de seus quartos, até que se envolve com Valquíria, a filha de um zelador de cemitério.

A primeira menção à guerra de que o personagem participou é feita logo no início do romance, quando ele lembra das camas de um hospital em que foi internado, todas colocadas lado a lado, "exatamente como no cemitério" (CARVALHO, 2008, p. 12). A partir daí, são constantes as rememorações da guerra até o fim do romance, mas em nenhum momento se diz onde ou quando ela teve lugar, e contra quem se lutava. São constantes, também, as reflexões do personagem sobre a falta de sentido das coisas "Sei que poderia aplicar-me em outras coisas, mas todas inúteis: tudo é inútil. Levei milhões de anos para chegar a esta sórdida conclusão, eu e meus antepassados" (CARVALHO, 2008, p. 13) - e sobre um vazio que o atormenta: "Lia nos jornais as grandes descobertas mas descobri que não me valiam nada, nem a ninguém - era a mesma condição humana o vazio sobre a cabeça e sob os pés, e sobretudo dentro, dentro da alma" (CARVALHO, 2008, p. 13). 0 teor dessas reflexões permite-nos pensar Vaca de nariz sutil como um romance existencialista: parece haver certa "afinidade", por exemplo, entre este narrador cético e Roquentin, personagem-narrador do romance $A$ Náusea (1938), de Sartre. Além disso, o sentimento de vazio vivido pelo personagem após voltar da guerra parece muito próximo do absurdo sobre o qual reflete Camus em $O$ mito de Sísifo (1942), ao tratar do "desacordo fundamental que separa o homem da sua experiência" (CAMUS, 2008, p. 114) - desacordo que possui a Segunda Guerra como 
cenário desolador: como observa Maurois (1965, p. 365), o desabrochar desse novo conflito, quando as feridas causadas pela Primeira Guerra sequer haviam cicatrizado, tornou ainda mais pungente a evidência de que o mundo carecia de um sentido apreensível, de um propósito, de uma razão de ser.

Assaltado por esse vazio, o narrador do romance não é capaz de se enxergar como ser homogêneo, vendo nascerem dentro dele vários outros "eus". Diante de sua perturbação, os médicos apresentam soluções: "A princípio, diziam, era a amnésia, depois a esquizofrenia - tantas palavras belas para camuflar este vazio, esta cratera de suas bombas que se abriu dentro de minha consciência: um buraco, eis o nome" (CARVALHO, 2008, p. 14). Observamos, no trecho destacado, a utilização dos termos "vazio", "cratera" e "buraco", que apontam para o ambiente concreto da guerra e, ao mesmo tempo, sugerem o espelhamento dessas "imagens de guerra" no interior do personagem. A fragmentação de sua identidade, no entanto, é de outra ordem que não a patológica. 0 "buraco" que se abriu em sua consciência não é resultado de um trauma, mas a consciência da falta de sentido do mundo, que parece ser potencializada na guerra: "eu me fitava nas suas lentes e me enxergava duplo, e via-me quádruplo nas suas retinas. E os que morreram em mim na guerra, há que enterrá-los também ou deixarei que fiquem insepultos?" (CARVALHO, 2008, p. 20). Por fim, as consultas com o médico resultam em um diagnóstico - um "diploma”, como observa ele em seu ceticismo - de esquizofrenia: "aquele vazio me espreitando como um convite ao salto mortal, o diploma de esquizofrênico no bolso junto com a medalha de ouro" (CARVALHO, 2008, p. 20).

Ao diagnóstico médico, todavia, o personagem chama "a verdade do médico" (CARVALHO, 2008, p. 32), indicando sua descrença em qualquer possibilidade de explicação/solução para o vazio que o atormenta:

Fico pensando comigo o porquê de certas coisas e não atino com verdade nenhuma que preste. Sei que há verdades de todos os tipos, para todos os gostos, é estender a mão e colher, como num bazar onde toda mercadoria fosse gratuita ou onde o dono fizesse vista grossa para o nosso pequeno furto. Teimo em examinar, porém, a mercadoria pelo direito e pelo avesso, o fato mesmo de ser gratuita me deixa suspeitoso e por fim cético, gratuito basta-me eu; e a boa vontade do dono acaba por cimentar minha perplexidade, ninguém dá a outrem uma verdade como quem dá uma maçã, por exemplo, ou o próprio rabo - isso eu sei por experiência (CARVALHO, 2008, p. 32).

A "experiência" a que o personagem alude no final do excerto diz respeito à prática sexual adotada pelos soldados no campo de batalha, descrita com pormenores 
em outras passagens do romance. Em uma dessas descrições, por exemplo, um general consente, às vésperas de um confronto, "num bacanal em grande estilo: era o que se poderia chamar uma ciranda copulativa, todos de mãos dadas - de mãos propriamente não" (CARVALHO, 2008, p. 29). Ao fim da orgia, os soldados se entregam à luta, e a "morte heróica" é ironizada pelo narrador: "O tenente foi um dos que morreram, como verdadeiro herói naturalmente; lutou como um bravo até o último instante, o esperma dentro das tripas" (CARVALHO, 2008, p. 29). 0 tom irônico, cheio de amargura, envolve praticamente todas as memórias do personagem que remetem ao front: "O silêncio era o pior, quando nos mandavam fazer silêncio: um assobio, mesmo em surdina, era crime de lesa pátria, não se podia nem peidar direito, espirrar então só em pensamento" (CARVALHO, 2008, p. 51). Ou então: "A princípio fora até divertido: podem matar à vontade, é só atirarem para frente, isto aqui é uma alça de mira, só atirem do joelho para cima" (CARVALHO, 2008, p. 50). Atestando a desilusão causada pela falta de sentido, o mote adotado pelos soldados era "Viva a merda!" (CARVALHO, 2008, p. 49) - termo, aliás, que aparece com recorrência nas páginas do romance:

\begin{abstract}
Era mais um vômito, o estrebuchamento de uma consciência morta a golpes de baioneta, dados não recebidos, pressentidos mais que dados, algo cuja verdade me escapava e era a minha única verdade. Quando vi eu gritava bem alto: MERDA!, duas, três, vinte vezes, com toda a força dos meus pulmões, como um cachorro voltado para a lua, sem saber bem o que fazia - simplesmente pela necessidade de gritar, como poderia ter gritado DEUS ou qualquer outra palavra sem sentido. Desde então fiquei sozinho para sempre, com a nova consciência que me pregaram a martelo no peito, este fundo abismo sem fundo, frio frio frio, como um ressuscitado em verdade mais morto do que nunca, sem passado, sem futuro, enxergando as coisas por um binóculo, tão distante tudo, todos (CARVALHO, 2008, p. 15).
\end{abstract}

Essa falta de passado ou de futuro a que se refere o personagem, a ausência de marcas precisas em sua narrativa informando, por exemplo, qual foi a guerra em que ele tomou parte, não parecem consequência de uma possível incapacidade de narrar gerada pelo trauma de sua experiência - hipótese que será discutida mais adiante. Desiludido, confrontado com o vazio, o abismo, a consciência morta, a solidão, ele se vê impossibilitado de construir para si uma identidade concreta, o que torna borradas suas memórias da guerra. Essa impossibilidade parece se concretizar também na figura de Aristides, seu companheiro de quarto na pensão. Ao refletir sobre ele, o narrador chega a pensar que o surdo-mudo talvez nem seja surdo-mudo realmente, optando por fazerse mudo, levando "seu ceticismo até as últimas conseqüências, sabendo como eu sei que 
nenhum dos dois sabe coisa alguma" (CARVALHO, 2008, p. 32). Essa hipótese é reforçada pela última passagem do romance: em um trem, um desconhecido puxa conversa, e ele se finge de surdo-mudo (CARVALHO, 2008, p. 109), fechando-se em um silêncio que atesta a futilidade de tentar significar.

\section{2 “0 oco": impossibilidade de narrar}

"O oco" é uma novela que, junto de outros textos, compõe o segundo volume em prosa escrito por Hilda Hilst: Kadosh, publicado em 1973. Ao longo de suas páginas, encontramos uma situação oposta àquela vislumbrada em Vaca de nariz sutil: o narrador de "O oco", também homodiegético, é um velho que habita uma praia sem nome e sem tempo, e que se demonstra impossibilitado de recuperar sua memória. Suas pernas possuem feridas severas - o que praticamente lhe impossibilita a locomoção, e um menino desconhecido, de quando em quando, vem fazer-lhe companhia e tratar de seus machucados. Em oposição ao narrador de Campos de Carvalho, que parece optar deliberadamente pela omissão, a narrativa de Hilst faz-se bem mais fragmentada: a exemplo de muitos textos de Samuel Beckett, há diversas passagens em que o velho narrador de "O oco" tenta construir determinada reflexão e, vendo que não se fez entender, tenta reconstruí-la, mas esta nova tentativa, sucedida por várias outras, acaba sempre em falha, o que resulta num amontoado confuso de palavras.

A guerra que o personagem tenta rememorar não teve grandes proporções: tratou-se de um pequeno conflito armado. A primeira tentativa de reconstruí-lo aparece nas primeiras páginas da novela: "São muitos, estão mortos. Não posso dar um passo, piso na mão de uma mulher, a boca aberta da mulher, a coxa escura de sangue. Olho para trás e vejo os soldados. Os cachorrinhos. A mancha vermelha outra vez. Acabou-se" (HILST, 2002, p. 136). Observamos, no trecho, a construção de frases curtas, de imagens fragmentadas, a não permitir a formação do todo. Podemos dizer que o sentido de "imprecisão" é semelhante àquele encontrado no romance de Campos de Carvalho, mas a linguagem é diferente. A "mancha vermelha" mencionada ao final do excerto representa a impossibilidade do personagem de recuperar suas memórias de forma satisfatória. Em vários momentos, quando ele tenta se lembrar de alguma coisa, a mancha o impede: "Às vezes tento aquela coisa outra vez. Aquela coisa é fechar os olhos e descobrir como é que eu vim parar aqui. $\mathrm{O}$ menino diz é aquela coisa outra vez? Eu 
digo é. Vai ver a mancha vermelha de novo, não adianta, pára com isso". E conclui: "É porque todas as vezes que eu tento me lembrar eu vejo a mancha vermelha" (HILST, 2002, p. 130). Ou ainda: "sei tão pouco a respeito de tudo, podem acreditar que se disse algumas verdades tais verdades não foram intencionais, de repente tenho vontade de despejar, mas sei que no meio do discurso vem a mancha vermelha" (HILST, 2002, p. 160). As imagens recuperadas pela memória do personagem, portanto, são difusas, resumindo-se a uma "mancha".

Ao refletir sobre o esquecimento, com base no texto "Rememoração, repetição, perlaboração", de Freud, Paul Ricoeur apresenta a possibilidade de se pensar a "memória impedida" como resultado da experiência traumática vivida pelo indivíduo:

\begin{abstract}
0 ponto de partida da reflexão de Freud é a identificação do obstáculo principal no qual o trabalho de interpretação (Deutungsarbeit) esbarra no caminho da recordação das lembranças traumáticas. Esse obstáculo, atribuído às "resistências do recalque" (Verdrängungswiderstände), é designado pelo termo "compulsão de repetição" (Wiederholungszwang); uma de suas características é uma tendência à passagem ao ato (Agieren), que Freud diz "substituir a lembrança". O paciente "não reproduz [o fato esquecido] em forma de lembrança, mas em forma de ação: ele o repete sem, obviamente, saber que o repete" (Gesammelte Werke, t. X, p. 129) (RICOEUR, 2012, p. 84).
\end{abstract}

Nesses termos, poderíamos pensar a incapacidade de se lembrar demonstrada pelo narrador de "O oco", simbolizada pela "mancha vermelha", como consequência de uma repetição constante, em forma de ação, da experiência traumática por ele vivida. Em comparação com o narrador de Vaca de nariz sutil, por exemplo, ainda que este tenha recebido um "diploma de esquizofrenia", a hipótese do trauma parece, aqui, mais aceitável - se bem que não de todo satisfatória, como veremos mais adiante.

Quanto ao conflito que teria gerado esse possível trauma, apesar de não ser possível reconstruí-lo com contornos precisos, os vários dejetos textuais "despejados" pelo narrador permitem-nos algumas inferências. Ao que tudo indica, ele era o capitão no comando de alguns soldados que tomavam conta de uma cidade. Um grupo de pessoas esfaimadas - "eu olhei para trás, vi as mulheres e as crianças, o rosto amarelo dos homens, os pés sangrando" (HILST, 2002, p. 180) - se apresenta a esses soldados, na praça da cidade, implorando por comida. Diante da recusa dos militares, o grupo, munido de facas, esboça um ataque, e é dizimado:

Termino. Deveria terminar, mas não. Vamos aos saltos. A pequena praça e o coreto. Depois: a pequena praça, o coreto e o chão de cadáveres. Eu havia dito: 
RESTABELEÇAM A ORDEM. A frase é como um funil. Vai até certo ponto (fim do tubo) alarga-se (começo e infinito da boca do funil). Se eu dissesse assim: restabeleçam a ordem sem violência. Um tubo apenas. Fechado numa das extremidades. Meu Deus... meu Deus... eu disse. E o outro: mas foi preciso... eles avançaram com as facas na mão... os soldados ficaram em pânico... foi preciso. A ordem restabelecida. Depois a coxa escura de sangue. A mão da mulher. A coxa escura de sangue. 0 gozo (HILST, 2002, p. 178).

Diante da ordem dada pelo capitão - "restabeleçam a ordem" -, portanto, os soldados exterminam os indivíduos que imploravam por comida. 0 "gozo" a que se refere o narrador, no final do excerto, é por ele atribuído a Deus: um Deus sádico que, segundo sua perspectiva, tem múltiplos orgasmos diante dos sofrimentos da humanidade (cf. HILST, 2002, p. 178). Em vários outros momentos da narrativa, o personagem faz referência a um "trono" que se encontra sempre "vazio". 0 conflito entre a perspectiva de um Deus sádico e de um Deus ausente remete ao título da novela (que, por sua vez, nos permite uma associação com o vazio de Vaca de nariz sutil) - "oco é uma coisa que não tem nada dentro" (HILST, 2002, p. 130) -, e que reflete a desilusão do personagem ao compreender a razão pela qual as guerras são travadas:

As guerras são feitas pra quê, afinal? Ah, sim, as guerras são feitas para matar os outros, porque de repente o mundo fica cheio de gente, gente que come, gente que enche as privadas, gente que cozinha e entope as caixas de gordura, e isso não é bom, é preciso matar as gentes para que as privadas fiquem limpas e as manilhas se esvaziem das penas de galinha e do pó de café. Que fique tudo limpo e brilhante por algum tempo. Enquanto cagam algures (HILST, 2002, p. 136-137).

A carga irônica que conduz todo o trecho denuncia o sem sentido da guerra: por meio de um "rebaixamento", as razões ínfimas apresentadas para o conflito anulam qualquer justificativa nobre a sustentá-lo. 0 oco a que se refere constantemente o narrador, portanto, parece refletir, assim como ocorre no romance de Campos de Carvalho, certa impossibilidade de significar, trazida à tona pela súbita consciência que o atinge acerca da falta de sentido que repousa sobre todas as coisas, o que leva sua identidade à dissolução - afetando, por conseguinte, sua memória.

\section{Nas malhas da dissolução}

Após a exposição e comentário de alguns excertos das duas narrativas aqui contempladas, procuraremos, nesta terceira parte de nosso estudo, refletir sobre as possíveis relações que se estabelecem entre o tema "memórias da guerra" e a 
configuração do sujeito na narrativa ficcional contemporânea. Tais reflexões podem ser iniciadas pela exposição de duas questões: primeiro, a estreita relação entre as memórias de guerra e a memória coletiva; segundo, a problemática diferenciação entre história e ficção.

Quanto à primeira delas, ao propor uma aproximação entre memórias de guerra e memória coletiva, estamos pensando, conforme observado por Paul Ricoeur, na "relação fundamental da história com a violência": "não existe nenhuma comunidade histórica que não tenha nascido de uma relação que se possa comparar sem hesitação à guerra. (...) A glória de uns foi a humilhação para os outros. À celebração, de um lado, corresponde a execração, do outro" (RICOEUR, 2012, p. 92). As memórias da guerra, assim, por dizerem respeito a acontecimentos que envolvem um grupo ou nação, parecem, a princípio, constituir vínculo mais estreito com a noção de memória coletiva. Nesse sentido, como pensar uma narrativa escrita em primeira pessoa - como é o caso de nossos dois textos - sob a perspectiva da memória coletiva?

Ricoeur (2012, p. 107-108) observa que existem três aspectos geralmente ressaltados em favor do caráter privado/individual da memória: primeiro, o fato de que as memórias parecem ser singulares, intransferíveis, e especificamente relacionadas à experiência vivida por cada indivíduo; segundo, a constatação de que, se a memória é passado, esse passado diz respeito a uma individualidade específica, permitindo a ela remeter a acontecimentos remotos de sua infância; terceiro, o fato de que o sentido da orientação individual na passagem do tempo está vinculado à memória. Ainda assim, segundo o autor, é possível, por analogia, relacionar à consciência individual "a memória coletiva como uma coletânea dos rastros deixados pelos acontecimentos que afetaram o curso da história dos grupos envolvidos" (RICOEUR, 2012, p. 129). Por conseguinte,

\footnotetext{
Uma vez reconhecida a transferência analógica, nada impede que essas comunidades intersubjetivas superiores sejam consideradas como o sujeito de inerência de suas lembranças, que se fale de sua temporalidade ou de sua historicidade, em suma, que se estenda analogicamente a minhadade das lembranças à idéia de uma possessão por nós de nossas lembranças coletivas (RICOEUR, 2012, p. 129).
}

Além disso, a partir da importância dada às ideias de Maurice Halbwachs, autor da obra A Memória coletiva, entra em cena a possibilidade de se pensar que a memória individual deriva, em certo sentido, da memória coletiva: “é a partir de uma análise sutil 
da experiência individual de pertencer a um grupo, e na base do ensino dos outros, que a memória individual toma possa de si mesma" (RICOEUR, 2012, p. 130).

A partir dessas reflexões, portanto, vislumbramos uma possibilidade de aproximação entre memória individual e coletiva, mas torna-se inviável relacionar tal aproximação a nosso corpus de análise. Mesmo que consideremos a narrativa construída sob perspectiva individual como parte da constituição da memória do grupo, a ausência de informações nos textos de Carvalho e Hilst impossibilita a analogia, pois esbarramos nas mesmas questões já formuladas: a quais grupos pertencem os indivíduos que ali se posicionam como narradores? Em que espaço e tempo podemos localizar esses grupos? Contra quais outros grupos eles entraram em conflito? Como já vimos, as respostas para tais questões permanecem inalcançáveis.

Mais adiante, ao tratar do "esquecimento", veremos que Paul Ricoeur estende sua interpretação de "memória impedida" do âmbito do individual para o coletivo: "Pode-se falar em traumatismos coletivos e em feridas da memória coletiva (...). A noção de objeto perdido encontra uma aplicação direta nas 'perdas' que afetam igualmente o poder, o território, as populações que constituem a substância de um Estado" (RICOEUR, 2012, p. 92). Ainda assim, parece-nos impossível interpretar a ausência de uma memória "concreta" nas obras aqui estudadas como consequência de um "impedimento" (traumatismo, ferida) que atingiu como um todo a memória do grupo a que pertencem seus narradores: se fosse o caso, seria possível, no mínimo, esboçar uma identidade para o grupo, ainda que sua memória coletiva tivesse sofrido danos.

Descartada a possibilidade de se pensar as memórias da guerra em Vaca de nariz sutil e "O oco" a partir de uma relação com a memória coletiva, resta a opção de considerá-los sob a perspectiva do testemunho, o que nos permite interpretar a falta de memória, como já vimos, como consequência da experiência traumática de seus narradores. Voltaremos ao assunto mais adiante. Por ora, reflitamos sobre nossa segunda questão inicial: a diferença entre história e ficção.

Pergunta Ricoeur: "que diferença separa a história e a ficção, se ambas narram?” (RICOEUR, 2012, p. 253). Não é nosso objetivo buscar uma solução para o problema. Limitamo-nos a registrar, a partir dele, a impressão de que parece possível, de fato, considerar um texto ficcional - e destacamos, aqui, aqueles textos ficcionais que compreendem relatos sobre guerras - como interpretação de um "fato histórico". 
Também essa hipótese, todavia, é inaplicável a nosso corpus: sequer podemos entrar no mérito de discutir a possibilidade de as duas obras aqui estudadas serem "válidas" enquanto interpretação do fato histórico narrado, pois não há fato histórico narrado. Nossas duas guerras são tão "anônimas" quanto os personagens que delas nos dão notícia.

Tanto a impossibilidade de pensar esses dois relatos em relação com uma memória coletiva quanto a impossibilidade de considerar neles a narração de qualquer "verdade histórica" encontram uma causa comum: o "esquecimento" de seus personagens-narradores. 0 esquecimento representa, segundo Ricoeur, o avesso sombrio da região bem iluminada da memória, atuando como ameaça constante: "o esquecimento é deplorado da mesma forma que o envelhecimento ou a morte: é uma das faces do inelutável, do irremediável" (RICOEUR, 2012, p. 435). Retomando o que foi exposto mais acima, durante a apresentação/comentário da novela "O oco", temos, como possível origem da "memória impedida", o trauma causado por determinada experiência vivida - que pode ser tanto individual quanto coletiva. A respeito do trauma individual em um contexto de guerra, Seligmann-Silva reflete sobre o testemunho, observando que, na tentativa de relatar situações traumáticas, há "uma falha na representação interna. Ocorre o registro, mas não a representação". Assim, o sujeito enclausura a experiência em uma espécie de "cripta interna", o que resulta na "fragmentação da narrativa" (SELIGMANN-SILVA, 2005, p. 71). Não nos parece, todavia, que esta seja a medida para pensar a falta de memória nas narrativas aqui estudadas. Nem tampouco a influência de uma possível "memória manipulada” (cf. RICOEUR, 2012, p. 455-459), que controlaria, numa espécie de "política de silenciamento", aquilo que pode ser lembrado e aquilo que deve ser esquecido.

Recapitulemos: em Vaca de nariz sutil, temos um narrador cético e desiludido, que é diagnosticado pelo médico como esquizofrênico. Apesar de, em alguns momentos, demonstrar confusão com relação a determinados fatos, ele não parece ter de lutar com sua memória para constituir um relato dos episódios por ele vividos. Pelo contrário, tais memórias parecem assaltá-lo constantemente. Esse narrador, portanto, provavelmente sabe o próprio nome, e sabe quando, onde e contra quem lutou. A ausência de tais informações em sua narrativa parece fruto de uma omissão deliberada (da mesma forma que a mudez de Aristides, e a sua própria mudez ao fim da narrativa): preocupa-o muito 
mais o vazio, tanto aquele que lhe invade as entranhas quanto aquele que paira ao seu redor, e a evidência do vazio torna irrelevante, ou mesmo fútil, a tentativa de edificação de um passado concreto.

Já nas páginas de "O oco", encontramos a situação inversa: o velho abandonado nas areias da praia nada sabe ao certo. Sua memória é um amontoado de dejetos e, por mais que ele se esforce para se lembrar, a "mancha vermelha" aparece e frustra suas tentativas. Em nenhum momento ele diz que não sabe o próprio nome, mas parece bastante provável que não saiba. Sua fala é extremamente confusa e, em várias passagens, ele tenta reformular o que disse anteriormente, com o intuito de ser mais claro. Por conta da falta de memória evidente, e da dificuldade para organizar as ideias, somos tentados a pensar sua "memória impedida" como consequência do trauma vivido (hipótese que não pode ser descartada), mas não podemos deixar de observar que, assim como ocorre com o narrador de Vaca de nariz sutil, as reflexões deste segundo narrador estão voltadas, em primeiro lugar, para o "oco" (aliás, muito próximo do "vazio" daquele), deixando as demais preocupações em segundo plano.

Mesmo considerando, portanto, uma possível aproximação com a situação do narrador de "O oco", a hipótese da falta de memória como consequência do trauma é insatisfatória. Para compreender a "incapacidade" demonstrada por esses dois personagens sem nome de narrar a guerra por eles vivida, temos de pensar na configuração de suas identidades - o que nos leva a uma reflexão sobre a identidade do sujeito na narrativa ficcional contemporânea.

Linda Hutcheon observa, em Poética do pós-modernismo - considerada uma das obras balizadoras das reflexões aqui pretendidas: “Já não se presume que o indivíduo perceptor seja uma identidade coerente, geradora de significados" (HUTCHEON, 1991, p. 29). Ao contrário, tais narradores "passam a ser perturbadoramente múltiplos e difíceis de localizar (...), ou deliberadamente provisórios e limitados - muitas vezes enfraquecendo sua própria onisciência aparente" (HUTCHEON, 1991, p. 29). É justamente essa a impressão suscitada pelos narradores aqui estudados: sujeitos cujas identidades parecem perder os contornos, desprovidos de nome, incapazes de construir referências precisas (chegando, no caso de "O oco", ao extremo da incapacidade de articular a linguagem de forma adequada). Fredric Jameson, no que pese seu posicionamento ideológico oposto ao de Hutcheon, também nos ajuda a refletir sobre 
tais identidades fragmentadas, explicando a frequente esquizofrenia (não aquela que é "a verdade do médico", como observa o cético narrador de Vaca de nariz sutil) do sujeito contemporâneo como consequência da perda de referências:

O significado, nessa nova visão, é gerado no movimento do significante ao significado. 0 que geralmente chamamos de significado - o sentido ou o conteúdo conceitual de uma enunciação é agora visto como um efeito-designificado, como a miragem objetiva de significação gerada e projetada pela relação interna dos significantes. Quando essa relação se rompe, quando se quebram as cadeias de significação, então temos a esquizofrenia sob forma de um amontoado de significantes distintos e não relacionados (JAMESON, 1997, p. 53).

Perdida a capacidade de referenciar, portanto, perde-se a capacidade de estabelecer relações precisas de espaço e tempo, o que afeta diretamente a construção da memória. Apesar do ceticismo do narrador de Vaca de nariz sutil, evidenciando sua lucidez - que poderíamos até considerar uma lucidez em excesso, pensando em Camus (2008, p. 49) - diante da "verdade do médico", podemos sim considerá-lo esquizofrênico - não no sentido patológico do termo, claro está -, e o mesmo vale para o narrador de "O oco".

Se o narrador de Vaca de nariz sutil escolhe fazer-se mudo diante de um mundo que se lhe configura esvaziado de sentido; se o narrador de "O oco" não consegue se lembrar de seu passado, e demonstra-se incapaz de construir uma narrativa coerente; e se as guerras que cada um deles tenta relatar prescindem de referências, de marcas precisas, de "ondes, quandos, comos e porquês", limitando-se a manchas - a exemplo da "mancha vermelha" constantemente mencionada pelo narrador de "O oco" -, esse conjunto de características aponta para uma tendência de se representar o sujeito na literatura contemporânea. Tendência que, conforme observa Nízia Villaça, apresenta como marcas: "indeterminação, fragmentação, descanonização, dissubstanciação do eu, o irrepresentável, a ironia, carnavalização, performance, desconstrução, imanência" (VILLAÇA, 1996, p. 26). Trata-se, portanto, de entender a incapacidade de se traduzir em texto a experiência vivida por conta de um "esfacelamento" da subjetividade. Minadas todas as possibilidades de certeza, frustradas as tentativas de se lançar mão a referências bem alicerçadas, a identidade do sujeito contemporâneo vê-se subitamente mergulhada em um torvelinho de impressões dispersas. Já não é mais possível se pensar um "eu" homogêneo, e a dissolução que se torna marca da subjetividade contemporânea acaba sendo, inevitavelmente, impressa também no texto literário - no caso específico 
aqui analisado, por meio da incapacidade demonstrada pelos narradores de constituir as memórias das guerras por eles vividas.

Se, em certa altura deste estudo, refletimos sobre uma possível semelhança entre história e ficção, devemos encerrá-lo observando que as duas obras sobre as quais aqui nos debruçamos são incapazes de narrar a história da forma como se espera que ela seja narrada: apresentando informações concretas sobre os fatos ocorridos, nomes, datas, lugares, detalhes precisos que permitam a "reconstrução" de um passado. O que não implica dizer que a narrativa contemporânea inviabiliza a construção de memórias de guerras com referências espaço-temporais precisas e um referencial histórico bem delimitado: a metaficção historiográfica em ascensão recente é um exemplo de que é claramente possível fazê-lo. 0 que pretendemos demonstrar, aqui, é que existe certa vertente $^{1}$ de nossa literatura contemporânea que opta por percorrer o caminho contrário, borrando a memória das experiências vividas, e embrenhando-se pelas malhas da dissolução.

\section{Referências}

CAMUS, Albert. $O$ mito de Sísifo. Trad. Ari Roitman e Paulina Watch. 6 ed. Rio de Janeiro/São Paulo: Record, 2008.

CARVALHO, Campos de. Vaca de nariz sutil. 4 ed. Rio de Janeiro: José Olympio, 2008.

HILST, Hilda. 0 oco. In: . Kadosh. São Paulo: Globo, 2002, p. 125-200.

HUTCHEON, Linda. Poética do pós-modernismo. Trad. Ricardo Cruz. Rio de Janeiro: Imago, 1991.

JAMESON, Fredric. Pós-modernismo: a lógica cultural do capitalismo tardio. Trad. Maria Elisa Cevasco. 2 ed. São Paulo: Ática, 1997.

MAUROIS, André. De Proust a Camus. Trad. Fernando Py. Rio de Janeiro: Nova Fronteira, 1965.

RICOEUR, Paul. A memória, a história, o esquecimento. Trad. Alain François [et al.]. Campinas: Editora da Unicamp, 2012.

\footnotetext{
${ }^{1}$ O romance $A$ céu aberto (1996), de João Gilberto Noll, não contemplado neste estudo por questões de extensão, apresenta também um narrador cujas "memórias da guerra" são borradas e imprecisas, o que reforça a possibilidade de se pensar na existência dessa vertente da literatura brasileira contemporânea sobre a qual aqui discorremos.
} 
SELIGMANN-SILVA, Márcio. Trauma, testemunho e literatura. In: O local da diferença: ensaios sobre memória, arte, literatura e tradução. São Paulo: Ed. 34, 2005, p. 63-118.

VILLAÇA, Nízia. Paradoxos do pós-modernismo: sujeito e ficção. Rio de Janeiro: UFRJ, 1996.

Recebido em março de 2014.

Aceito em junho de 2014. 